\title{
Mulheres emparedadas e seus espaços de memória
}

\author{
As mulheres ou os silêncios da \\ história.
}

PERROT, Mic helle. Trad. Vivia ne Ribeiro.

São Paulo: Edusc, 2005. 519 p.

Trata-se de uma obra interessantíssima, composta de cinco partes em 23 capítulos, basea dos em estud os public a d os a nterio mente, pela própria autora e por outros pesquisadores que se debruçaram sobre questões atinentes à mulher, como Michel Foucault e das várias correntes do feminismo. A autora discorre sobre os espaços de memória ocupados pela mulher ao longo da história e seus emparedamentos. Mesmo silenciada, a mulher conseguiu registrar experiências onde the era permitido, restritas, evidentemente, a o espaço doméstico, ao privado. Esse espaço, paradoxalmente, vem a ser o grande celeiro de sua própria libertação. É o que vamos tentar colocar aqui.

$\mathrm{Na}$ Introdução, Michelle Perrot faz uma espécie de arqueologia de todo o processo de resistência trilhado pela mulher, passando por váriasfases, a té chegara o feminismo, na década 
de 60 do século passado. A Parte I da obra, chamada de "Traços", é composta de quatro capítulos e centra-se nas correspondências das filhas de Karl Marxe nos diários da jovem Ca roline Brame, que viveu em Paris entre 1847 e 1892. A autora detecta o pouco espaço dispensado à mulher na narrativa histórica tradicional, muito ma is comprometida com a cena pública, com a guerra e a política, ainda que a República francesa tenha dedicado a ela parte do seu acervo iconográfico com está tuas de silhueta feminina.

Como o registro históric o sempre privilegiou os eventos acontecidos na esfera pública e a mulher fic ou reduzida ao espaço privado, ela nunca foi chamada a fazer parte da cena histórica e teve de desenvolver estratégias de sobrevivência naquilo que lhe restou: o lar. Por isso, a memória do privado coube à mulher. Era ela quem cultuava os mortos e suas tumbas, sendo a forma de comunicação dominante a oralidade, passada, geralmente, de mãe para filha. Mas muita coisa se perdeu devido a mudanças de casa, ao desprezo porse tratarde mulher e ao embaraço pelo conteúdo legado. As cartas deixadas pelas filhas de Karl Marx, por exemplo, foram quase todas extra viadas, uma vez que emitem juízos sobre as manias e fraquezas do pai do materialismo dialétic 0 . 0 mesmo não aconteceu, por exemplo, em relação às cartas de Tocqueville trocadas com Gustavo de Beaumont

Enquanto os homens da burguesia, no século XIX, têm o hábito de colecionar quadros, livros como distinção e sinônimo de suas conquista sec onômicas, as mulheres preoc upamse com a roupa branca e os objetos, em uma ânsia de reter suas vidas em "mil na das": estojos, nos quais guardam "mechas de cabelo, flores secas, jóias de família", e depois fotografias, croquis e cartões-postais de viagens e outras miudezas.

As correspondênciastêm a possibilidade de diálogo, buscando uma troca. Têm a capacidade de apresentar o que o espetáculo esconde, porque explicitam "as fadigas do herói, suas dúvidas e o seu dia-a-dia" (p. 46). O desenvolvimento da imprensa, por outro lado, trouxe à mulher do século XIX ma is um desa fio: 0 domínio da escrita, a tra vés de correspondências, c artões-posta is e diários, impondo-lhe uma nova forma de memória.

O paido comunismo, Karl Marx possuía três filhas: J enny, Laura e Eleanor. Em 1868, La ura casa com o francês Paul Lafargue, e J enny, em 1872 , desposa Charles Longuet, a tivo militante da
Intemacional e do King's College de Oxford, e migra para a França. Eleanor, a ma is nova, após a morte dos pais e de Jenny, a imã ma is velha mantém correspondência com Laura. São 69 cartas ávidas por notícias da imã. Suplica, em 1881, que apenas um cartão-postal the seria suficiente, mas logo depois condena a secura de comunicação através de postal.

A participação dos maridos, nessas correspondências, reduzia-se ao post-scriptum quando mandavam notícias ao "Caro Senhor Marx," por exemplo, sobre a Internacional Socialista. São correspondências que têm "um tom de conivência, uma ironia zombeteira que cai bem em uma família tão imbuída de sua superioridade" (p. 47). E a mpla admiração e necessidade de estarem à altura das leituras do pai é o que denotam as cartas das filhas a Marx, a quem tratavam como Mestre, Velho Mestre, Mohr, Challey, Old, Nick, entre outras denominações, sempre em sinal de respeito.

Marx possuía convicções bem burguesas em relação às filhas. A ma is nova, Eleanor, Tussy, como era carinhosamente chamada, fol impedida de casar com um homem basco, pobre, chamado Lissagoray. "Marx partiu o coração de sua filha e irritava-se com a sua depressão" (p. 50), e ela cometeu suicídio, ingerindo veneno "para cães", em 31 de março de 1898. Elea nor viveu com Ed ward Aveling, que era separado de uma primeira esposa e nunca teve a a ceitação da família desta e, principalmente, do seu pai. Já a figura da esposa de Marx é pouco proeminente, sendo tratada pelas próprias filhas como um tanto bizarra, por sua distração e sua oc upação com as a gulhas a costurarpara as filhase netos, a inda que, no final da vida, seja vista por elas como terna e dedicada à família.

É interessante destacarque dadosque não constam dos manuais de história, nas correspondências, aparecem de forma bem clara e capazes de causar restra nheza a os leitores mais a tentos, como o comportamento de Marx em relação aos pretendentes das filhas. 0 casamento de sua filha Laura com Paul Lafargue II, "o Negro", por suas ascendências cubanas, por exemplo, só ocorre depois que a família do noivo lhe dá garantias da boa situação financeira. Em carta de 23 de agosto de 1866, Marx, escrevendo a Engels, afima: "O pai [Laforgue] escreveu-me de Bordeaux. Ele pediu para seu filho o título de noivo e apresentou-me, do ponto de vista financeiro, condições muito favoráveis". Engels era tão a migo de Marxque chegou, para evitar um escândalo, a perfilhar um filho natural 
deste com a criada Helene, sobrinha de sua mulher Lizzie. Com a morte de Lizzie, Helene assume a casa de Engels. Mas Eleanor logo suspeita de que essa "nova formação familiar" seria uma tentativa de controle sobre os escritos de seu pai, Karl Marx.

As correspondências trocadas deixam transpa recer as mágoas, as desilusões, as dores dessas sensíveis mulheresque, a pesarde vela rem o socialismo, como colaboradoras, estiveram condicionadas aos papéis a elas destinados: maternidade, partos sucessivos, com corpos cansados e adoecidos. Perrot fala das contra dições vividas poressas mulheres que não são capazes de escreveraberta mente entre imã s sobre seus próprios ventres, seus corpos, ainda que a doença ocupe amplo espaço em suas missivas. As irmã s deixam entrever a angústia da vida doméstica em suas cartas, usando essa forma de comunicação para desabafo. Porém, a pesar das crític as às condicionantes das mulheres, as herdeiras de Marx não eram feministas. As feministas da época, como Paule Mink, Séverine ou Annie Besant, sofriam repulsa das imãs.

Eleanor, das três imãs, foi aquela que mais sofreu com as pressões de uma época, sendo impedida de casar com o homem da sua vida. Após a morte do pai, entretanto, vive em liberdade. Viaja pelos Estados Unidos e Suécia, conhece Aveling, por quem tem forte apego: porém, descobre um casamento secreto deste com uma jovem a rtista. As dific uld a des financeiras sempre presentes, a depressã o nervosa no verão de 1881, a segunda crise, em 1882, tudo isso exaurem-lhe as forças, levando-a ao suicídio. Além de Eleanor, Laura também se matou, em 25 de novembro de 1911, com 66 anos, após uma noite de festa, junto a Paul, seu velho companheiro.

O diário, outra forma de comunic ação permitida à mulher do século XIX, tende a firmarse como uma maneira de expressão pessoal e se trata, a o mesmo tempo, de uma agenda, uma vez que não se limita a registrar apenas o que passou, mas também a previsão das atividades futuras, como uma espécie de organização do tempo, tão necessária a um século em que a noção de progresso se instaura.

Caroline Brame (1847-1892) tinha o hábito de escreverem cademos escolares- 36 a o todo, e depois os encadernou, usando uma flor diferente para identificar os dias. Um desses foi adquirido por Georges Ribeill, companheiro de pesquisa de Perrot, em um mercado de pulgas, e talvez tenha permanecido ali por ter sido confundido com outros livros por seu capricho de encadernação. No entanto, o que ma is chama a atenção no mesmo é a "expressão de um sentimento, de um desejo, o esboço logo abandonado de uma aventura, e o consentimento final ao irremediável destino das mulheres: um casamento a rranjado que se procura tra nsformarem uma união escolhida" ( $p$. 90).

A escrita do diário de uma moça do século XIX detém-se em enumerar ocupações do cotidiano, como ir às compras, fazer visitas, freqüentar jantares, etc., sendo o espaço reservado a confissões altamente policiado, de acordo com o que era esperado de uma moça Não ra ro, Ca roline escreve: "Meu Deus, há neste momento algo que eu desejo" (4.1.1866); "Meu Deus, o que escrever aqui!... Posso abrir meu coração!" (15.1.1866). A decência determina o que dizer até no diário!

Constituía fator de distinção feminina saber ocupar os dias. Em 1888, c ircularam anuários como Le Livre d'Or des Salons, que prescreviam os ritos a serem seguidos pelas mulheres burguesas com a rotina de visitas, como Ca roline relata em seu diário de 21.12.1864: "Dia perfeita mente a tord oa nte [...] Prec isei fa zer visitas o dia inteiro!". Ela comparava as obrigações socia is às "pesa das cruzes que se deve carregar".

A jovem era muito influenciada pelos prec eitos do catolic ismo. O século XIX, porém impõe e justifica a utilida de do tra ba lho em nome do progresso. "Ainda que a Igreja não tenha realmente elaborado uma teologia do trabalho no século 19 , sua mensagem é a tra vessa da pelos novos valores. Ora, o ócio é, naquele momento, um valor contestado. A Igreja o condena assim como os soc ia listas" (p. 12).

A Parte 2, "Mulheres no trabalho", compõese de seis capítulos dedicados a pesquisas que se voltaram ao trabalho das mulheres no século XIX e, principalmente, à incorporação do "gênero" no setorterciário da economia, a partir de entã o o grande geradorde emprego para as mulheres, principalmente, em seus escritórios. 0 corpo, ou melhor, o corpo sexuado passa a ser objeto de podere de desejo nasfábricas daquele século. Ainda que o droit de cuissage (direito à primeira noite) nunca tenha constituído uma categoria jurídica real, como sublinhou, com justiça, Ala in Boureau, sua representação impregna o imaginário social, o imaginário dos executivos que acreditavam poder tudo. Nessas circ unstâncias, as pa la vra sutiliza da sem relação à mulher, muitas vezes, reproduzem imagens a inda da era do feudalismo. 
Visto como insignificante e complementar à remuneração masculina, o trabalho feminino em fábricas, inferiorizado, estigmatiza a mulher a inda ma is porque lhe impõe condições que em nada a dignificam e, ao mesmo tempo, não a a mparam na maternidade. As mulheres, enquanto grupo, pouco se envolviam com as greves: entre 1871 e 1890, de 173 reivindic ações somente das mulheres, havia a adesão de 5,9\% delas. Já em greves mista s há uma a desão ma ior: em 361 greves, no mesmo período, 12,3\% contam com a partic ipa ção das mulheres. Foram partic ipantesnaspassea tas, usando voze gestos, conseguindo bandeiras, vociferando contra os patrões e até quebrando vidraças. Entretanto comportavam-se ma is como esposas, não havendo, de fato, engajamento sindical.

No cômputo geral, as mulheres militantes do século XIX mais bem organizadas em suas reivindicações eram aquelas que, de alguma forma, estavam vinculadas a homem trabalhador. Elas podiam ser membros de comissão, oradoras de reuniões ou mesmo responsá veis por sindicatos, mas controladas, podemosdizer, em suas rupturas. Tra ta va-se, nesse caso, de uma insubordinação a partir da ética do homem. A sociologia profissional das greves femininas, ligadasà indústria da seda e a o grupo têxtil-vestuá rio, vincula-se a o protestantismo e a o radicalismo, sendo vistas, muitas vezes, pela própria mulher, como uma forma de ela sermais livre e falar mais claramente sobre suas demandas, encontrando apoio, assim, nos republicanos locais.

Em 1886, em Lyon, a greve geral a presentase apoiada nos dois sexos solidários, tendo as picadoras da Casa Calle-Mouco adesão do sindic a to dossapa teiros, de tendência a na rquista. Porém, o mais importante movimento de greve foi aquele desencadea do em 1889, em Fougères, quando as picadoras param por melhores salários, enquanto os homens aderem ao movimento não porque estivessem insa tisfeitos com seus próprios salários, mas antes por solidariedade a o grupo feminino trabalhadorda Casa Haussaye, da área da produção de sapatos.

Entre 1874 e 1890 vá rios conflitos oc orreram como nos "conventos de seda", somente para moças, mantidosporreligiosas; na Casa PochayBruny, em Pa viot (Isère); em intema tos destina dos à smoças solteiras; e nas "casemas" para oscasa is operá rios. As tra ba lha doras das ma nufa turas do tabaco, por outro lado, gozavam de relativas vantagens, uma vezque tero Esta do como patrão significava garantia de alguns direitos, como a aposentadoria portempo de serviço.

Na Exposição Universal de 1867, um delegado operário assume a seguinte fala refletindo o modo de pensarda época: "O destino da mulheré a família e a costura [...]. Ao homem, a madeira e os metais, à mulher, a família e os tec idos". Essa divisã o dospa péis sexua is impunha, para ela, um modelo a serseguido tanto na esfera pública quanto na privada.

A Parte 3, "Mulheresna cidade", é composta de cinco capítulos, em que são tra ta dasquestões relativas à mulher, procurando fazer uma diferença entre o polític o e o jurídico, enqua nto instâncias do poder. Assim, a s esferas do públic o e do privado amparam-se na questão do poder e refletem, antes, a relação entre os sexos, em suas divisões de papéis, de ta refas, de espaços. No século XIX, a distinção entre o público e o privado, bem como a higenização, constituem formas de poderque se imiscuem em uma rede tenta cular do controle. Logo, o lugar do poder não está somente na mão do Estado, mas se espraia no corpo social sem que se possa estabelecer o seu limite, como já dizia Michel Fouc a ult.

Nessa dimensão do poder, encontram-se de forma transversal, as relações entre os sexos, determinadas não somente pelo gênero: "construção sociocultural, produto das relações sociais desenvolvidas no tempo e que se pode, conseqüentemente, desconstruir" (p. 264). Michelet exclama: "as mulheres: que força!" Tal o poder difuso e eficaz que elas detêm sobre os costumes. A elas sempre foi a tribuído 0 enigmátic o: "A Mulheré a Outra, a estrangeira, a sombra, a noite, a a rma dilha, a inimiga" (p. 265). Assim, o sentimento de alteridade feminina reforça-se no século XIX, principalmente pelo impulso contínuo exercido pela a mpliação de seu domínio, sendo o movimento feminista somente uma conseqüência de todo um processo, ainda que, em certo sentido, a República promova uma reg ressão a os direitos femininos já conquista dos no Antigo Regime.

É preciso destacar que o "exercício do poder" não ocorre em uma cartografia prévia, pois tanto homens qua nto mulheres "negociam" seus limites de ação. Inegavelmente, a Igreja promoveu a mulher, atra vés da figura da Virgem Maria, fortalecendo "uma forte consciência de gênero" (p. 272). Se, por um la do, impõe uma resignação, uma renúncia à mulher, por outro, Ihe a tribui poder, dignida de e a necessida de da fidelidade masculina às suas esposas. Constituise, dessa forma, uma exaltação da diferença feminina, mas, ao mesmo tempo, a promoção 
de "guardiãs do patriarcalismo". A escola laica da Revolução também promove a inserção da mulher como professora primária e secundária, sendo uma senda para o feminismo.

As mulheres do século XIX exercem o poder "possível". Muitas delas são mães "a busivas", que se valem da tirania sobre uma linhagem, seus empregados e, muitas vezes, nas classes populares, sobre os maridos, que lhes entregam todo o sa lá rio e são controla dos por ela sem suas ações. A hegemonia feminina, então, ocorre do espaço privado para o público. Baudrillard, em De la séduction, fala acerca do poder exercido pela mulher através de seu corpo e da ascendência deste sobre o casal. O poder das mulheres last but not least, isto é, último mas não menos importante, mantém-se em uma intrinca da rede de contrapoderes. Paradoxalmente, o contrapoder exercido pela mulher no espaço doméstic 0 , restrito, foi aquele que lhe entreabriu - espaço público, por meio da filantropia religiosa. Então, dialeticamente, o privado faz parte do público e o religioso ta mbém do secular. Dessa forma, justifica-se o "slogan" feminista de que o "privado é público".

George Sand escreve em 1848: "Como os costumes chegaram a este ponto em que a mulher reina no maior número de famílias, e que há abuso desta autoridade conquistada pela ha bilida de, pela tenacidade e pela astúcia, não há nada a temerque a lei se encontre à frente dos costumes. Ao contrário, para mim, ela se encontra atrasada em relação a eles" (p. 278). Assim, a mulher do século XIX, socialmente, era a utoridade na família, mas, juridicamente, não, uma vez que era impedida de votar e não dispunha de outros direitos de cidadã. E a filantropia burguesa tira a mulher de sua casa para "visitar ros pobres, os prisioneiros, os doentes. Traçava, na cidade, itinerários permitidos e a bençoados. A a mpliação dos problemas socia is, no século XIX, transforma este hábito em exigência" (p. 280).

É importante destacar que a filantropia, a princípio, reduzia-se à classe do lazer, isto é, à s burguesas, entretanto, a mplia-se para ascla sses médias, que se encarregam de divulgarpreceitos da economia doméstica liberal, via caridade. Para Ca roll Smith-Rosenberg, as New Women de 1880-1890 são as filhas das New Bourgeoises Matrons das décadas de 1850-1880. Isto é, a filantropia deu uma espécie de "consciência de gênero" às mulheres, sendo, muitas vezes, uma "consciência feminina".

A Parte 4, "Figuras", em dois ca pítulos, tra ta de duas figuras importantes, que, apesar de mulheres, não se deixaram calar diante das imposições de uma época. São elas Flora Tristan e George Sand, que se a proximam em vários de seus traços: revolta acerca da condição da mulher, reivindicação de uma justiça social que levasse em conta a condição operária e a reivindicação de uma étic a na política. A história das mulheres foi escrita a partir da voz de pioneiras, que ansiavam quebrar o silêncio. Elas podem serfla gradas, em seus percursos, a tra vés de retratos, biografias, nesse caminho de mudez.

Quando Flora Tristan publica Promenades dans Londres (Passeios em Londres), em 1840, a pesquisa social toma-se corrente tanto na França quanto na Grã-Bretanha. "Para govemaro corpo social, é preciso conhecê-lo; para conhecê-lo é prec iso estudá-lo em seu conjunto; conhecer sua origem, sua história, sua populaçã o, seu temitório, seus costumes, seu espíito, sua força, sua riqueza" (p. 365). Flora Tristan encama essa tendência e escreve em suas Promenades... sobre a importância da pesquisa de campo: "O papel importante que a Inglaterra desempenha nosfaz desejar conhecê-la" (p. 366). Além das Promenades dans Londres, Flora deixou a notações, na forma de diário de viagem, para um livro que se chamaria Le Tour de France, produto de um périplo por diversas cidades no Sul da França com o objetivo de traçar uma radiografia da classe operária em seu "aspecto moral, intelectual e material". Tal livro só foi public ado em 1973.

George Sand, por sua vez, representa uma resistência pouco vista, em uma época em que a mulheraparecia como mero complemento na cena social. Figuras como Guizot e Tocqueville viam a política como coisa para homem. O último, em suas lembranças de 1848, dizia: "Eu detesto as mulheres que escrevem, sobretudo aquelas que disfarçam as fraquezas de seu sexo num sistema" (p. 382). Entretanto, George Sand constituía uma exceção a essa a va liação preconceituosa desse revolucionário, o que a deixa va bastante lisonjeada. George Sand viveu entre 1804 e 1876 e participou de parte do périplo percomido pela Revolução Francesa. Desde 1830 a inda como Aurore Dudevant, assumiu-se como republicana. Em 1840, toma-se socia lista.

A Parte 5 e última da obra, "Debates", é composta de seis capítulos e versa sobre vários temas, que encerram cada um deles a visão de conjunto, isto é, a questão da mulher, a teoria das esferas do público e do privado, a construção da identidade feminina à luz do social, do biológico, além de uma retrospectiva feita por Perrot da presença da mulher nos séculos XIX e 
$X X$. Perrot, que trata dos percalços da mulher suas indefinições, bem como das estratégias utilizadas para ocupar as franjas do poder, fala da certeza de que a mulher, ou melhor, o segundo sexo, oc upou na história do Ocidente um papel suplementar, em uma arena dominada pelo homem, detentor do poder, do espaço público, portanto

Os Women's films centram-se na representação das mulheres em filmes de Hollywood, que encamam, com várias desditas, asagruras da dona-de-casa e mãe sempre com um happy end marcado pela felicidade. Betty Friedan, em seu livro The Feminine Mystique, de 1963, insurgira-se contra esse feminine mystique, sendo tal obra considerada, por isso, um marco teórico do feminismo norte-americano. Não se pode esquecer, entretanto, que o Segundo sexo, de Simone de Beauvoir, foi publicado em 1949!

Ainda são publicadas, no século $X X$, nos Esta dos Unidos, obras sobre a esfera privada da mulher e seu grau de influência. Entre elas, destacam-se Public Man e Private Woman, de J ean Bethke Elshtain, ou as teses de Carol Gilligan em A Different Voice: Women's Conceptions of Self and Morality, de 1977. A década de 1970, com o seu feminismo radical, foi às últimas conseqüências com o feminismo lésbico e homossexual em geral. 0 feminismo cultura lista dos anos 1980, na Itália, também segue essa linha, ainda que seja via criação literária, com Hélène Cixouse Mônic a Wittig ou com a pesquisa psic a na lítica de Luce Irigaray.

No início de sua produção intelectual, Michel Fouc ault não se preocupou com a questão das mulheres, ou mesmo com a diferença entre os sexos. Entretanto, obras como História da loucura, Nascimento da clínica, Dito e escrito, entre outras, foram utilizadas em grande número de pesquisas envolvendo mulher e diferença entre os sexos. Os Estados Unidos mantêm a disc ussão em tomo dos Women's Studies e dos Gender Studies. Os estudos baseados nos pósestrutura lista se a plic a dos a os estud os de gênero são mais de natureza teórica do que histórica. Mesmo na França, é possível encontrar estudos entre filósofos, além de Foucault, como Deleuze,
Guattari. Entre as mulheres, podemos citar os trabalhos de Lois Mac Nay, Foucaultand Feminism (1992), ou de Caroline Ramazonaglu, Up Against Foucault (1993), e Sandra Borkty, Suzan Bordo, Irene Diamond ou Nancy Hartsock.

Uma obra importante na linha de Michel Foucaulté a de Thomas Laqueur Making Sex. Body and Gender Fron the Greeks to Freud, public ada em 1990. Ele defende a idéia de que a diferença sexual deve-se menosà biologia do que à política e à cultura. Passamos de uma concepção monista (século XVI a XVIII), com um únic o gênero e duas modalidades, para a dualista, a partir do século XIX. A dualista, porseu tumo, defende que há dois sexos, dotados de identidade física e moral, e que esses dois sexos têm uma suposta justificativa na biologia, capaz de transformaro discurso naturalista em divisão sexual da sociedade e um determinado modo de ver o mundo, que legitima e delimita as esferas do público e do privado. Em sua crítica à modernidade, afirma que não há objetivos na tura is, mas constituíd os disc ursivamente em sociedade. Nesse sentido, tanto a mulherquanto o homem não existem, daía recusa à "etemidade de uma sexualidade feminina", essencialista e universal.

Portanto, a obra As mulheres ou os silêncios da história, de Michelle Perrot, rastreia os vánios recursos de silenciamento impostosà vozfeminina na história do Ocidente. Entretanto, apesar de restrita à esfera priva da, conseguiu articula r-se a partir do que the foi reserva do, isto é, o doméstico, a filantropia e a própria Igreja. Esses espaços definidos de socialização, quando tensionados, constituíram fator de engendramento para o domínio público posterior, muito devido à contribuição de figuras como George Sand e Flora Tristan na França do século XIX. Eos estudos feministas, em suas várias correntes, propõem uma clivagem na forma de organizar o político, porque "o privado é político".

Sandra Sacramento Universidade Estadual de Santa Cruz, Ilhéus, BA 